\title{
OBJECT ORIENTED MODELLING AND SIMULATION OF HYDROPOWER PLANTS WITH RUN-OF-RIVER SCHEME: A NEW SIMULATION TOOL
}

\author{
Juan Garrido, Ángel Zafra*, Francisco Vázquez \\ Dpto. de Informática y Análisis Numérico. Universidad de Córdoba. Spain \\ *Endesa Generación UPH Sur. Spain
}

\begin{abstract}
This paper presents the design of a component library for modelling hydropower plants, and describes the development of a new simulation tool for small hydropower plants with a run-of-river scheme. After reviewing the desirable features of simulation, an approach based on an object oriented modelling language, like EcosimPro, is presented. A general model of hydropower plant with run-of-river scheme is created with this component library. It provides the possibility of choosing a specific number of turbines and spillway gates. In this way, several hydropower stations of similar operating characteristics can be simulated using this same general model. It is expected to obtain interesting information in simulation like the reservoir level, water flows, turbine efficiencies, and so on. In addition, a graphical user interface has been designed in order to operate this general model more easily, to configure plant parameters and to simulate the plant behaviour under different conditions. Three real stations have been used as real examples for validating the model and testing the simulator: hydropower stations of Villafranca and El Carpio (Córdoba, Spain) and Marmolejo (Jaén, Spain).
\end{abstract}

Keywords: object oriented modelling, component library, hydropower plants, simulator.

\section{Introduction}

It is well known that there are powerful reasons for modelling and simulating: testing and optimizing the design of a system before its construction, preventing design errors, improving quality, reducing costs, evaluating performances, predicting behaviours, training operators in different operating conditions and so on. Simulation is a very useful tool in those cases in which experimentation costs are very high, due to very expensive equipments or the impossibility of stopping the system, like in power plants. Due to this reason, Endesa Generación Company proposed to the University of Córdoba (Spain) the development of a software tool for simulating the performance of a set of small hydropower plants. All these plants belong to the South Hydraulic Production Unity of Endesa in Spain and they are placed in Guadalquivir River with a low head run-of-river scheme, showing many common characteristics. In addition they do not need big dams and they have a small environmental impact.

In the run-of-river scheme the turbine only produces power when the water is available and provided by the river. When the river flow falls below some predetermined value, generation ceases [1]. Low head schemes are typically built in river valleys. Two technological options can be selected. Either the water is diverted to a power intake with a short penstock, or the head is created by a small weir which is provided with sector gates and an integrated intake, powerhouse and fish ladder (Fig. 1). Because of the fact that the gross head in these stations is small, Francis or Kaplan turbines are commonly chosen [2]. In normal operation, this type of plant tries that the river water flow passes through the turbines while the upper water level is being controlled in order to have a minimum head. However, when the river flow is greater than the turbine discharges and the reservoir level exceeds its highest reference, the governor system of the gates comes into the scene and controls the reservoir 
level.

Object oriented modelling $(\mathrm{OOM})$ is quite recent paradigm, whose utilization has been spread during the nineties and applied to model power system and their applications [3-5]. A hydropower plant is a combination of related components as generators, turbines, gates, control systems and so on. With the OOM approach every modelled component is treated as an object, and a complete model of a general run-of-river hydropower plant can be built by connecting objects, as in physical plants [6]. In addition, this modular development facilitates the maintenance and update of each component [7]. Simulating this general model, it can be obtained much information like reservoir level, flows, pressures, head losses in different components, turbine efficiencies and so on. Then, an optimization of the system operation can be carried out.
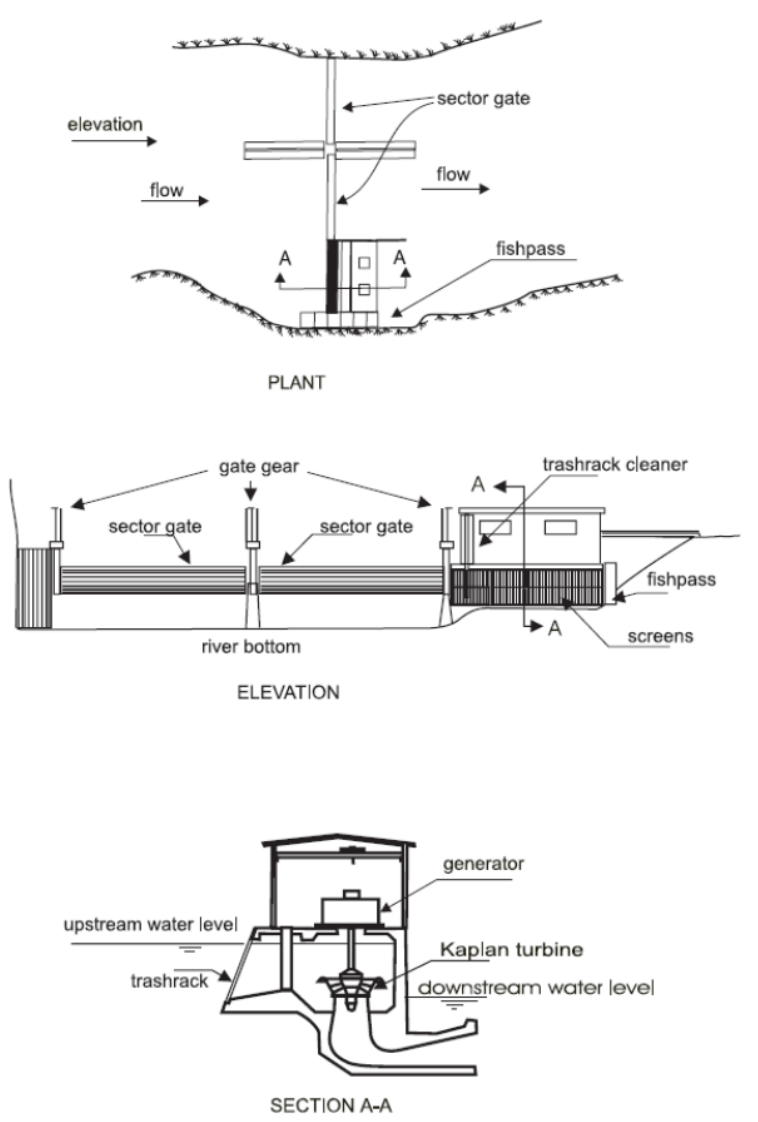

Figure 1: Low head run-of-river scheme

On the other hand, the improvements and developments of power plant automation systems make operation easier. But this fact comes along with an increasing tendency for the operator of losing knowledge about his plant [8]. Hence the need of graphical user interfaces (GUI) for power system analysis and operator training. In order to simulate the previously mentioned model of general hydropower plant, a new simulation tool is developed. It also can be used as a trainer for plant operators, as well as to support and enhance hydropower engineering education.

In a previous work of the authors [9] a component library and a simulation tool of hydropower stations were introduced after being used for modelling and simulation of Villafranca power station. Now the simulator is debugged and some aspects of the library have been improved. In this paper all the work is presented in a more appropriate way and other plants are simulated showing good results too. This paper is organized as follows: in section 2 equations used for modelling some of the elements of a hydropower plant are presented. Section 3 shows the development of a component library of hydropower plants using EcosimPro and the modelling of a whole station with run-of-river scheme. In section 4 the GUI for this general plant model is described. In section 5 the model and simulator are validated using experimental measurements of three hydropower plants. Finally, in section 6 , the conclusions are summarized. 


\section{Plant description and mathematical modelling}

The main elements of a hydropower plant and the equations used for modelling them are described next. All these models are built on the basis of physical principles of conservation of mass, energy and momentum. Partial differential equations are usually used to model hydropower plants, especially when long pipes belong to their constructive parts. However, in this work authors avoid them and use simplified models because in hydropower plants with run-of-river scheme, these conduits are not usually very long.

\subsection{Dam}

The description of this component is based on the mass conservation principle. If water density is considered constant and input $q_{\text {in }}$ and output $q_{\text {out }}$ dam flows are known, its instantaneous volume $V$ can be calculated integrating (1). From the level versus volume table of the dam, its water level is estimated by interpolation. In table 1 the data provided by Endesa for the Villafranca station are shown.

$$
\dot{V}=\sum q_{\text {in }}-\sum q_{\text {out }}
$$

Table 1: Height above sea level (m) versus volume $\left(\mathrm{Hm}^{3}\right)$

\begin{tabular}{|c|ccccccccccc|}
\hline Height (m) & 0 & 10 & 20 & 30 & 40 & 50 & 60 & 70 & 80 & 90 \\
\hline 115.00 & - & - & - & - & 0.00 & 0.02 & 0.05 & 0.09 & 0.12 & 0.15 \\
116.00 & 0.18 & 0.21 & 0.24 & 0.27 & 0.31 & 0.34 & 0.37 & 0.41 & 0.45 & 0.49 \\
117.00 & 0.53 & 0.57 & 0.62 & 0.66 & 0.71 & 0.76 & 0.81 & 0.87 & 0.93 & 0.99 \\
118.00 & 1.05 & 1.12 & 1.19 & 1.26 & 1.34 & 1.42 & 1.50 & 1.59 & - & - \\
\hline
\end{tabular}

If the heights (above see level) of the dam water surface and the dam outlet are known, output pressure $p_{\text {out }}$ is calculated by (2), in which $\rho$ is the water density $\left(\mathrm{kg} / \mathrm{m}^{3}\right), h$ is the water head $(\mathrm{m})$ over the outlets and $p_{0}$ is atmospheric pressure.

$$
p_{\text {out }}=\rho \cdot g \cdot h+p_{0}
$$

\subsection{Gates}

Gates are devices to control or stop the flow of water. In power plants with run-of-river scheme they are usually used to control the level of the upper water reservoir when this control is not only possible with the turbine discharges. Its main dynamic is the principle of mass conversation or, for a constant density, the sum of input flows equals the sum of output flows (3). The gross head $h$ over the gate is calculated depending on the input and output pressures according to equation (4). These pressures depend on the upstream elevation and the downstream elevation with regard to the gate elevation.

$$
\begin{array}{r}
\sum q_{\text {in }}=\sum q_{\text {out }} \\
h=\left(p_{\text {in }}-p_{\text {out }}\right) /(g \cdot \rho)
\end{array}
$$

The instantaneous opening op (in $\mathrm{m}$ ) is obtained from (5) by integration of its movement speed (vel), which depends on the command signal (opening, closing or stopping). This command signal determines the sign of the speed that the gate must reach (vel_ref): positive, negative or zero. This speed vel_ref and tau are parameters of the gate.

$$
\begin{aligned}
\dot{o p} & =\text { vel } \\
\dot{v e l} & =\frac{\left(v e l \_r e f-v e l\right)}{t a u}
\end{aligned}
$$

Several types of gates have been modelled, like sliding or radial gates. The expressions for their output flow $q_{\text {out }}$ and their flow coefficient $C$ are the only differences between them. The flow of a sliding gate is given by (6), where $L$ is the gate length and $g$ is the gravitational constant in $\mathrm{m}^{2} / \mathrm{s}$.

$$
q_{\text {out }}=C \cdot L \cdot o p \cdot \sqrt{2 \cdot g \cdot(h-o p / 2)}
$$


In power plants with run-of-river scheme a gate automation system opens or closes the spillway gates, in order to keep the water level of the dam between two references. When the water level exceeds the higher reference, the gates start to open a step (of $0.25 \mathrm{~m}$ for instance) until the level falls under the higher reference. When the water level falls under the lower reference, the gates start to close a step, one after another, until the level reaches the lower reference.

\subsection{Turbine}

Hydraulic turbine is a rotative machine moved by water, in such a way that the hydraulic energy from a water flow or water head is converted into mechanical energy. Input power $P_{i n}$ is given by (7), where $h_{g}$ is the gross head over the turbine in $\mathrm{m}, q$ is the discharge in $\mathrm{m}^{3} / \mathrm{s}$ and $\rho$ is the water density in $\mathrm{kg} / \mathrm{m}^{3}$. In such expression it is necessary to know the gross head over the turbine, which is calculated from (8), where $p_{\text {in }}$ and $p_{\text {out }}$ are the input and output pressures in $\mathrm{Pa}, a_{\text {in }}$ and $a_{\text {out }}$ are the inlet and outlet cross-sections areas in $\mathrm{m}^{2}$, and $z_{\text {in }}$ and $z_{\text {out }}$ are the inlet and outlet heights above the sea level in $\mathrm{m}$.

$$
\begin{gathered}
P_{\text {in }}=\rho \cdot g \cdot h_{g} \cdot q \\
h_{g}=\frac{p_{\text {in }}-p_{\text {out }}}{g \cdot \rho}+z_{\text {in }}-z_{\text {out }}+\frac{(q / a)_{\text {in }}^{2}-(q / a)_{\text {out }}^{2}}{2 g}
\end{gathered}
$$

IEEE recommends the usage of certain turbine models [10], but they do not usually recognize blade angle response in Kaplan turbines, and since the dynamic behaviour of a turbine is rather complex, for its definition the use of three experimental data tables have been preferred. These tables have to be obtained for each model of turbine to be simulated. From interpolation of these tables, the following parameters are calculated:

- $\quad$ Turbine efficiency $\eta$ (\%) depending on the turbine gross head and turbine discharge. The data of this table for the turbines of Villafranca power plant are plotted in Fig. 2.

- $\quad$ Flow coefficient $K$ depending on the gate position gp (\%).

- $\quad$ Reference runner blade position (\%) from the conjugation law between wicket gate opening (\%) and runner blade position (\%), that is the blade versus gate characteristic (blade in on a cam to get optimal efficiency). As example, Figure 3 shows this characteristic in Kaplan turbines of Villafranca station.

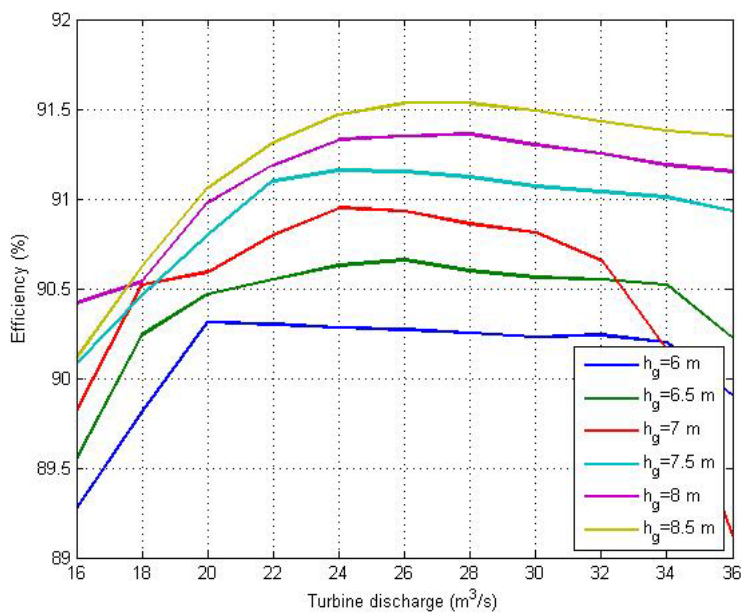

Figure 2: Turbine efficiency versus turbine discharge for different gross head in turbines of Villafranca station 


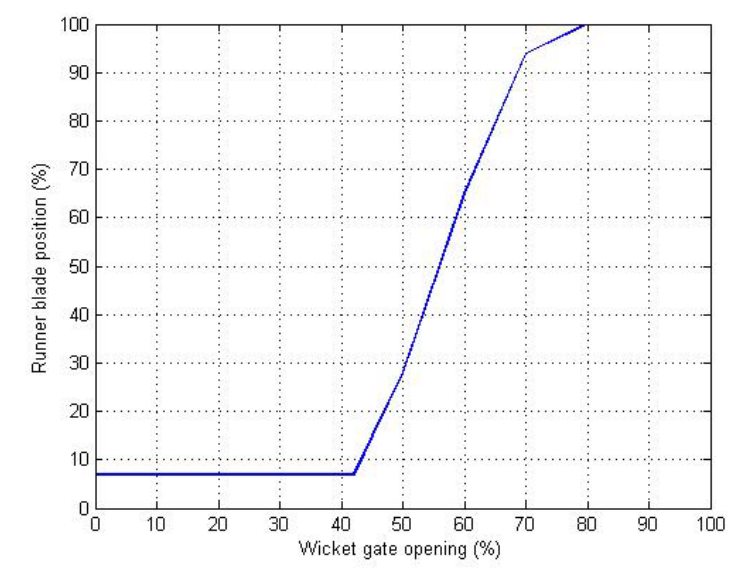

Figure 3: Blade versus gate characteristic in Kaplan turbines of Villafranca station

In Kaplan turbines, blade angle control has significant impact on the turbine power response. The turbine model was developed to represent this effect. Blade angle affects water discharge through the turbine and turbine efficiency in coordination with gate opening. Ultimately, both affect turbine power output [11]. When the flow coefficient $K$ is linearly interpolated from the previous table, the turbine discharge $q$ can be approximated by (9). The input and output flows are equal according to the principle of mass conversation (3). Then, turbine efficiency can be interpolated from one of the previous tables depending on the known discharge. A penalization coefficient is applied to this efficiency when the blade position is different from the optimal position according to the blade versus gate characteristic. Finally, the power output of the hydro turbine-generator is calculated by (10).

$$
\begin{aligned}
& q=K t(g p) \cdot \sqrt{h_{g}} \\
& P_{\text {out }}=\eta \cdot P_{\text {in }}
\end{aligned}
$$

\subsection{Synchronous generator}

The electric synchronous generator joined to the turbine shaft converts mechanical energy into electrical energy. Its behaviour is different depending on whether it is connected to the electrical grid or not. The dynamic of its rotor is given by (11) where $w$ is the rotational speed in $\mathrm{rad} / \mathrm{s}, J$ is the generator inertia in $\mathrm{kg} \cdot \mathrm{m}^{2}, P_{\text {in }}$ is the power coming from the turbine (in $\mathrm{W}$ ), and $P_{r}$ is the power of the resistant torque, which depends on the generator state.

$$
\dot{w}=\frac{P_{i n}-P_{r}}{J \cdot w}
$$

If the generator is with no load and without any brake, $P_{r}$ is proportional to the product of a loss factor multiplied by the speed $w$ to the power of two. On the other hand, if the alternator is connected to the grid $P_{r}$ is equal to input power, in such a way that $\dot{w}$ is zero and the rotational speed keeps constant and equal to the corresponding value for a frequency of $50 \mathrm{~Hz}$. In this way, it is supposed that the hydroelectric unit practically has a constant speed (in normal operation conditions) when it is connected to the electrical grid. This is due to the great inertia of the grid which accelerates or decelerates the generator when its frequency tends to deviate from $50 \mathrm{~Hz}$. For this reason, this generator model is only valid for units in grid-connect mode and not in standalone situation.

\subsection{Hydro-turbine governor system}

The variables for control actuation are wicket gate position (and runner blade position in Kaplan turbines). The gate position is the main control variable for the unit's flow rate. The blade position is used to extend the efficiency in Kaplan models. In order to control the position of the wicket gate, Francis turbines usually have a pilot valve and a servomotor. Kaplan turbines have another pilot valve and servomotor for the runner blade control. The model in Fig. 4 shows the servo dynamics of the gate [10,11]. The blade servo model is similar. The parameter $T g$ is the main servo time constant, and $T p$ is the pilot valve and servomotor time constant, all in 
seconds. The speed limit of the servomotor and the maximum and minimum gate opening are represented by two saturation blocks.

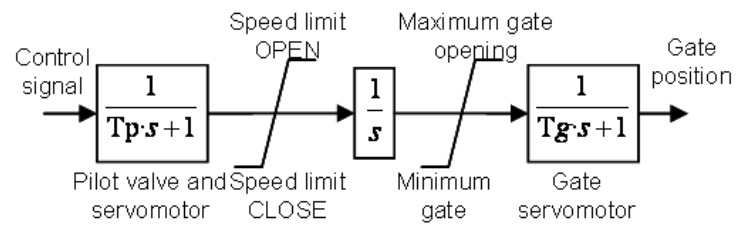

Figure 4: Block diagram of the pilot valve and servo of the gate

The gate position is controlled by an automation system, or by a PID control loop; the runner blade position is controlled by a PID control too, that receives the gate position in order to get the reference of the runner blade position according to the blade versus gate characteristic for optimal efficiency.

During the starting and stopping, the PID control of the gate tries to reduce the error between the turbine speed (or frequency) and the speed reference. When the unit is connected to the electrical grid, its operation is accomplished by an automation system in which a water level controller is implemented. The speed control loop is modified by this level control, which is based on ordering opening or closing pulses to the gate servomotor with a frequency inversely proportional to the level error. Figure 5 shows the control scheme of a Kaplan unit when it is connected to the electrical grid. The upper control level of the automation system it is not depicted. In the case of using a Francis turbine, elements related to the blade position $(b p)$ would not appear.

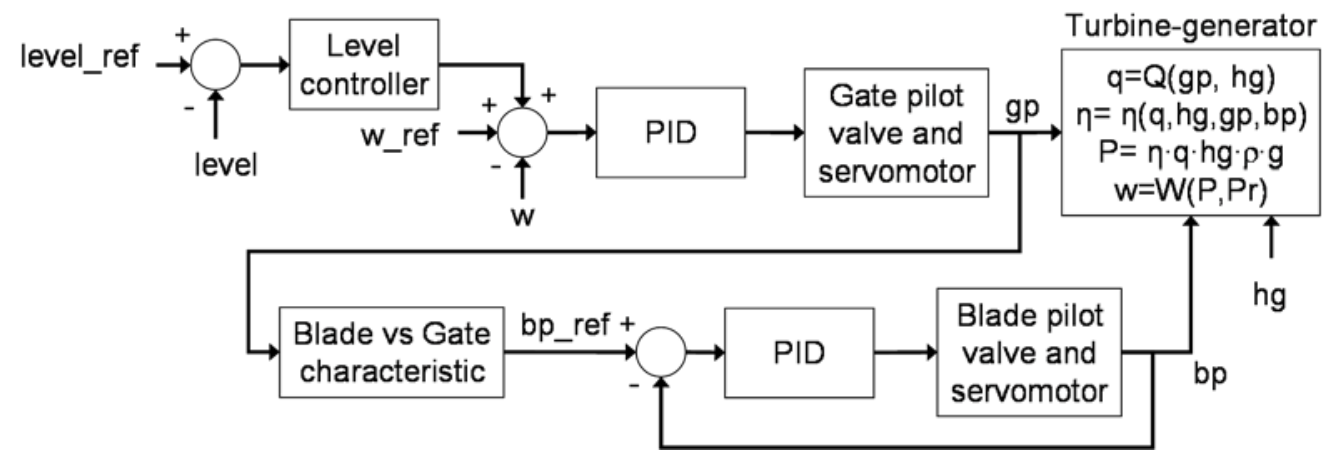

Figure 5: Control scheme of a Kaplan unit in grid-connected mode

Basically, the automation system program is structured in three parts according to the state of the hydrogenerator (starting, stop or coupled to the electrical grid) and the transitions between states. If the group is stopped and the dam level is over the group reference level, the group must start. On the other hand, if the level is below the stop level, the group is ordered to stop.

In starting state, the automation system enables the frequency (speed) PID controller with a reference of $50 \mathrm{~Hz}$. The output signal of this controller passes through the automata (PLC) and then is applied to the gate servomotor. The gate opening makes frequency increases towards the reference. When the frequency is between 45 and $55 \mathrm{~Hz}$ the automation system tries to couple the group to the grid. If the frequency is maintained within a reduced range (49.5 and $50.5 \mathrm{~Hz}$ ) during a configured waiting time, the hydroelectric unit is coupled. Otherwise, the PID control continues controlling the frequency (speed). In Fig. 6 the block diagram of this stage is shown. 


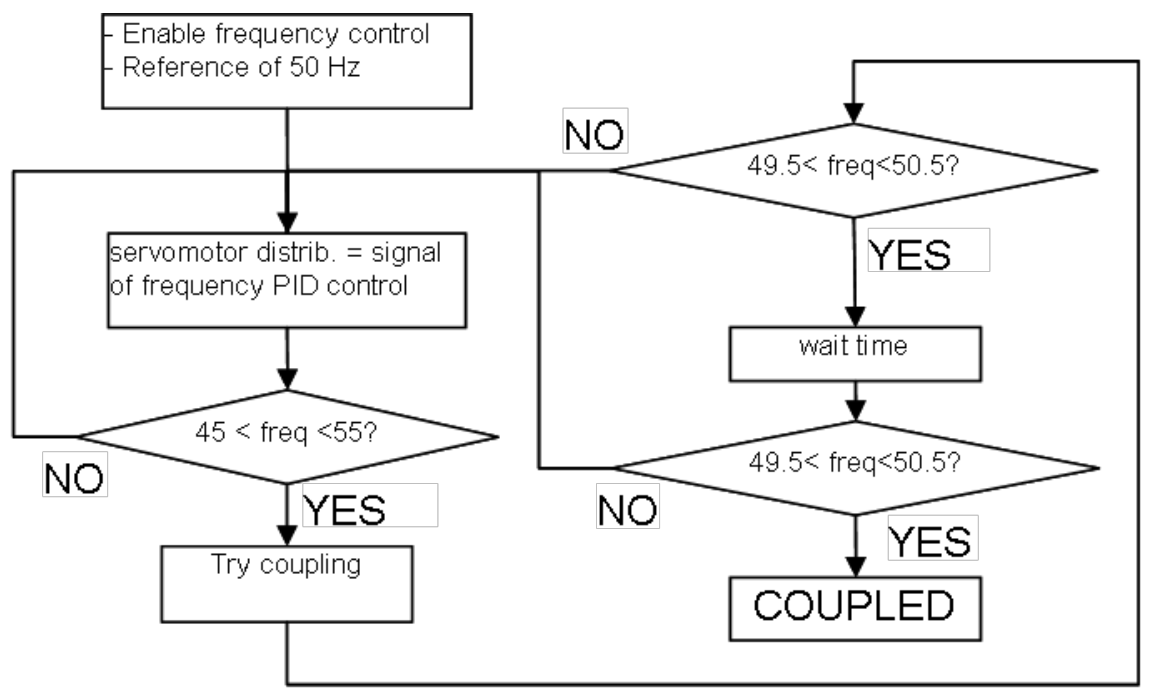

Figure 6: Block diagram of starting stage

In the large hydropower plants the turbine controller operates on the gate servomotor modifying the turbine torque in order to get a power balance between the different groups and to maintain the frequency in its nominal value (power-frequency control). When a small hydropower plant is connected to the grid, it must be taken into account that its power is very small in comparison with the grid, and so it can not produce an appreciate effect in the system regulation. Therefore the control strategy of this kind of plants is designed to get the best tracking of the available flows to discharge, what is achieved by a control system which tries to maintain a constant water level in the weird. The performance of this control system is quite different from traditional frequency-power regulator, due to great inertia of the elements inserted between the controlled variable (water level) and the manipulated variable (gate servomotor).

When hydro generator is coupled to the grid, the gate is open until reached a minimum load. Then gate servomotor is regulated according to the level controller of the automata PLC. This control tries to keep the reservoir level equal to a reference level (the starting level). But all groups have not the same reference level. This fact can make that two groups works with different loads (power), or that only the power of one group is affected by changes in the reservoir level.

If the level falls bellow the stop level, the hydro generator state changes to stop state. First, the gate is closed to load 0 (10-20\% of power) and then the group is disconnected from the grid. The speed control with zero speed reference regulates the servo of gate and when a frequency of $12 \mathrm{~Hz}$ is reached, a branch is applied to stop the group until the frequency falls below $2 \mathrm{~Hz}$. Finally the speed control is disabled.

\subsection{PID Controller}

A PID controller tries that a variable tracks a set point according to the feedback error signal $e$ between the reference and the variable. It includes a component proportional to the error, an integral component that accumulates as the error persists in time, and a derivative component that accounts for the rate of change in the error. The derivative term of PID controller amplify high frequency signals, so a low pass filter is applied. Besides, in order to improve the controller response, this term only depends on the output to be controlled and filtered $y_{f}$. It is kwon as PI-D structure. Its expression is as follows

$$
u=P+I+D=K p \cdot e+\frac{K p}{T i} \int e \cdot d t-T d \cdot \frac{d y_{f}}{d t}
$$

where $u$ is the control signal, $K p$ the proportional gain, $T i$ the integral time constant and $T d$ the derivative time constant.

\section{Implementation in EcosimPro}


Object oriented modelling philosophy is used to develop a component library for hydropower plants according to the descriptions of the previous section. Several OOM advantages, like inheritance, encapsulation and modularity, have been used in the library design. Due to the great complexity of a hydropower station, it is very advisable to make use of these OOM features. The basic idea of implementation in EcosimPro is to decompose the described plant into components that are as simple as possible and then to start from the bottom up, connecting basic components into more complicated classes, until the top-level model is achieved. In addition, the use of classes (or abstract components) allows reusing code. A class is a programming abstraction that captures the important and common attributes and behaviour for a set of similar components [12].

EcosimPro supports both modelling using existing components in various libraries and detailed modelling by equations. The graphical diagram layer and the textual layer using EcosimPro language (EL) can be efficiently combined. EL is a natural modelling language that simplifies the component modeller's work. EL statements that clearly describe a component or port are elaborated internally to check for consistency and validity. Continuous equations are sorted, modified symbolically and checked to ensure there are no problems such as singularity, high index, redundant variables, etc [13].

Time domain simulation is an important tool for hydropower plant analysis [14]. After compiling the model, the set of equations is formulated as a system of differential-algebraic equations (DAE), written as follows:

$$
\begin{gathered}
F\left[t, y(t), y^{\prime}(t)\right]=0 \\
y\left(t_{0}\right)=y_{0}
\end{gathered}
$$

To integrate and solve this set of equations and simulate the model, EcosimPro uses a variable step integration method called DASSL. The solution method is based on replacing the time derivative (13) with an approximation by differences and then to solve the resulting equations for time $t_{n}$ using implicit Newton iterations. The following example, using a backward difference for $y$ ', in case equation (13) becomes:

$$
F\left[t_{n}, y_{n}, \frac{y_{n}-y_{n-1}}{t_{n}-t_{n-1}}\right]=0
$$

where $n$ represents steps in time. The system of DAEs given in (13) has been approximated by a system of nonlinear algebraic equations (14) where $y_{n}$ represents the vector of unknowns in time $n$. DASSL can also approximate the derivative y' using the $k^{\text {th }}$ order finite difference, where $k$ is between 1 and 5 . The order $k$ and time step $t_{\mathrm{n}}-t_{\mathrm{n}-1}$ is automatically chosen by DASSL at each step on the basis of the behaviour of the solution. The experiment's communication interval is a maximum limit for the current integration time step.

The implicit iteration technique used to solve the system of non-linear algebraic equations is Newton's method. To obtain the iteration matrix required by Newton's method, EcosimPro calculates a Jacobian numerically using finite differences.

Next, the component list of the developed library is shown in Fig. 7 with their inheritance relationships. Although, this library is specially designed to model hydropower plants, all models are transparent and can be modified or extended. The components are:

I. Component interface ports:
a. Hydraulic port
b. Analog port
c. Digital port

II. Components of the dam:

a. Dam: upper water reservoir

b. Lower water reservoir

III. Hydraulic structures:

a. Conduction abstract component:

1. Dam intake

2. Dam outlet 
3. Spillways

4. Gate abstract component:

- Sliding gate

- Radial gate

5. Turbine abstract component:

- Kaplan/Francis turbine

6. Pipe abstract component:

$$
\begin{array}{ll}
\text { - } & \text { Pipe } \\
\text { - } & \text { Bend } \\
\text { - } & \text { Contraction } \\
\text { - } & \text { Expansion }
\end{array}
$$

IV. Control systems:

a. Controller abstract component:

1. P controller

2. PI controller

3. PID controller

b. Gate automation system

c. Hydroelectric unit automation system

V. Electromechanical equipments:

a. Synchronous generator

b. Signal converter

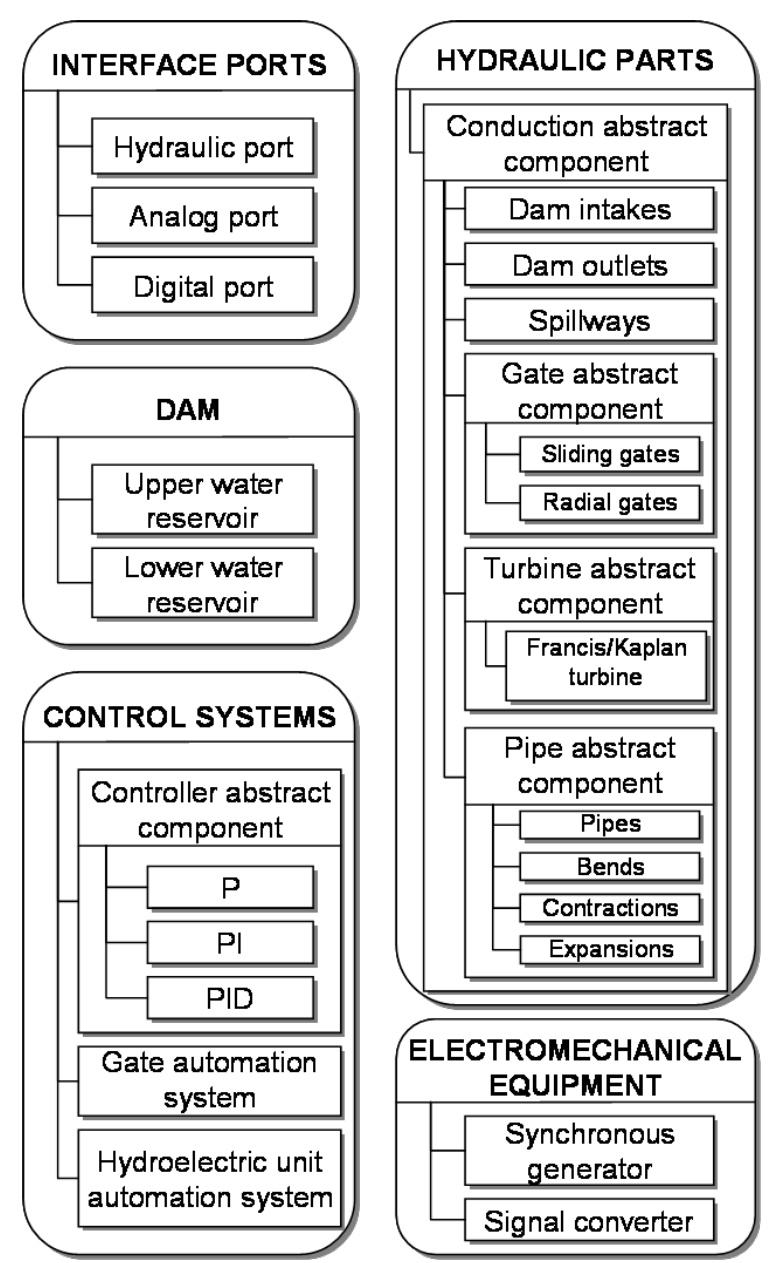

Figure 7: Inheritance relationship of library components 


\subsection{Ports}

EcosimPro components are connected to each other by means of interfaces known as ports. They define the variables that the components will share, without prejudicing any kind of computational order. Three different ports have been defined: hydraulic, analog and digital ports. Hydraulic ports are used for hydraulic measurements, where there are two relevant variables: water flow and pressure. The water pressure is the same in all the ports connected to the same node (15), while the sum of all the water flows should be zero (16).

$$
\begin{aligned}
& p_{1}=p_{2}=\ldots=p_{n} \\
& q_{1}+q_{2}+\ldots+q_{n}=0
\end{aligned}
$$

Analog and digital ports are used to share analog or digital signals, respectively. The signal is equal in all ports of a same node, as in expression (15). During the model translation equations (15) and (16) originating from the port definitions, are automatically generated and added to the other equations of the model.

\subsection{Dam}

This component is modelled according to its description in subsection 2.1. Figure 8 shows the EL code. Two hydraulic ports (input and output) are declared in the PORTS section. Also an analog port is used to share the dam level with other components. Parameters like initial level are specified in DATA section, while dynamics variables, like level or volume, are declared in DECLS section. In CONTINUOUS section the dynamic equations (1) and (2) are implemented, and spline interpolation is carried out in order to estimate the instantaneous level from the level versus volume table.

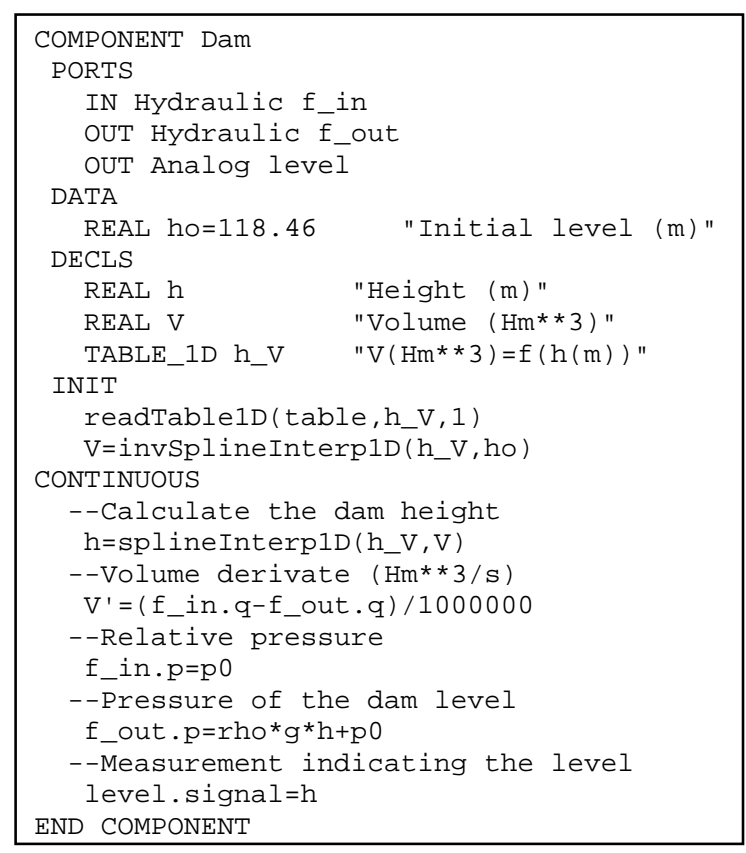

Figure 8: EL code for the dam component

\subsection{Conduction abstract component}

This element does not really exist, but it is used to gather the common features of any hydraulic component like pipes, turbines or gates. These last components will be declared as derived from it, so they will inherit its behaviour and attributes. In this abstract component, one input and output hydraulic ports are specified, and the flow conservation principle (3) is implemented: input flow and output flow are the same. Figure 9 shows the EL code. 


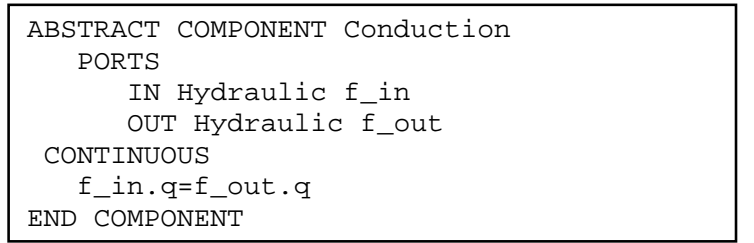

Figure 9: EL code for the conduction abstract component

\subsection{Dam outlet}

Turbines, gates or spillways could be connected to the dam at different levels, and so the pressures in each outlet should be different, too. The dam component only has an output hydraulic port where the pressure variable indicates the dam level above the sea level. To solve this problem it is possible to declare several output hydraulic ports in the dam component at different heights. However the number of outlets would be limited and the dam component would not be very flexible.

To avoid this, it has been preferred to create new components, dam outlets, which are connected to the only output port of the dam. Any element taking water from the dam should be connected through a dam outlet component, where the corresponding outlet height is specified as a parameter and the proper output pressure is calculated according to this level.

Since any dam outlet should have two hydraulic ports (input and output) and its input and output flows are the same, this component inherits these attributes from the conduction abstract component. A similar modelling is carried out in the lower water reservoir and its intakes.

\subsection{Gates}

As there are several types of gates but they have common characteristics, a gate abstract component has been created. In addition, it derives from the conduction abstract component. The general gate has an input port to order its opening, closing or stopping, and an output analog port to indicate its opening degree. Width, maximum opening and movement speed are some parameters which can be configured in gate components. In order to calculate the gross head and the opening degree, equations (4) and (5) are implemented in its CONTINUOUS section.

Then, specific gate components, like sliding or radial gates, are developed from the gate abstract component. They inherit all the attributes of this class and only the expressions for their output flow and their flow coefficient have to be specified. For instance, Figure 10 shows the code of a sliding gate component, where the output flow is given by (6). In this code a ZONE statement is used as a conditional statement. If the opening degree is higher than the gross head over the gate, the output flow is obtained according to the expression (17).

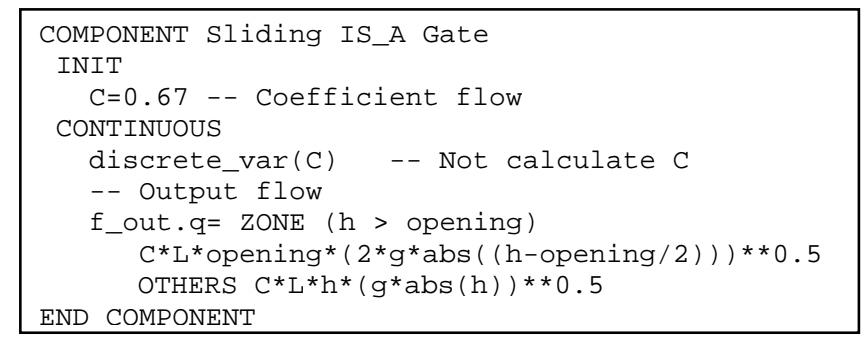

Figure 10: EL code for the sliding gate component

$$
q_{\text {out }}=C \cdot L \cdot h \cdot \sqrt{g \cdot h}
$$

\subsection{Turbines}

A turbine abstract component, which comes from the conduction abstract component, is defined with the common parameters and basic equations of any turbine. Parameters like inlet and outlet cross-sections areas, inlet and outlet heights above the sea level are specified in the DATA section of the component. It has an analog port to share the output power. In the CONTINUOUS section the equations (7), (8) and (10) are implemented in order to calculate the gross head and the input and output powers. 
By inheritance, another component called "Kaplan” is defined from this one. It collects the specific features of a Kaplan turbine, although it can be configured as a Francis turbine canceling the runner blade action. In this component the dynamics depicted in Fig. 4 about pilot valve and servomotor of the wicket gate, and runner blade, are implemented in differential equations. Therefore, it also consists of two input ports to operate on the gate servomotor and the runner blade servomotor, and two analog output ports to share the positions of the gate and the blade.

In addition, in this component the data tables explained in subsection 2.3 are specified. They are used to estimate the turbine efficiency, the flow coefficient and the reference blade position by interpolation. These interpolation commands, as well as, the flow discharge calculation by (9) are in the set of equations of the CONTINUOUS section.

\subsection{Pipes}

The pipe abstract component, which derives from "conduction" too, has the common features of any closed component with an internal flow like pipes, bends, contractions or expansions. They are modelled based on (3) and the principle of conservation of energy, assuming an incompressible fluid and a rigid conduit. Although they are not used in the hydropower plant model of this paper, these components have been modelled and included in the library to increase its versatility.

In order to calculate the output pressure, the head losses $h_{r}$ are estimated by equation (18), where $l$ is the length of the element (m), $f$ is the pipe friction factor, $K r$ is the accidental loss coefficient, $d_{\text {min }}$ is the smallest diameter of the cross-section areas (m) and $q$ is the flow through the pipe. Head losses are the sum of friction losses (Darcy-Weissbach’s equation) and accidental losses [15].

$$
h r=0.0827 \cdot f \cdot l \cdot \frac{q^{2}}{d_{\min }^{5}}+\frac{K r}{2 \cdot g} \cdot\left(\frac{4 \cdot q}{d_{\min }^{2} \pi}\right)^{2}
$$

To estimate the pipe friction factor, it is also necessary to know whether the flow is laminar or turbulent depending on the Reynolds number. If this number is greater than 2300 the flow is considered turbulent, otherwise laminar. When the flow is turbulent, Colebrook's formula is used to obtain the friction factor.

When head losses are obtained, the output pressure $p_{\text {out }}$ of the component is calculated by

$$
\begin{aligned}
& p_{\text {out }}=p_{\text {in }}+\left(z_{\text {in }}-z_{\text {out }}\right) \cdot \rho \cdot g+ \\
& \rho \cdot\left(\left(q_{\text {in }} / a_{\text {in }}\right)^{2}-\left(q_{\text {out }} / a_{\text {out }}\right)^{2}\right) / 2-h r \cdot g \cdot \rho
\end{aligned}
$$

where $q$ is flow, $a$ cross-section area and $z$ height. The components derived from this abstract component, like pipes, bends or expansions, only differ in the $K r$ coefficient.

\subsection{Controllers}

A controller abstract component with the fundamental aspects of a controller is created: two analog input ports for the controlled variable and the reference signal, and one analog output port for the manipulated signal. From this one, a proportional controller is defined by inheritance, adding the proportional action to the controller output in the CONTINUOUS section. In the same way PI controller derives from the proportional control. The controller output is modified because now it is the sum of the proportional and the integral actions. In order to change an equation declared in a father component, the equation which specifies the controller output is declared as a virtual equations. In the PID controller component, this equation is modified again and the output is the sum of the proportional, integral and derivative actions. Also, the filter equation of the derivative action is included. Figure 11 shows part of the code of the PI and PID components, and the use of virtual equations. 


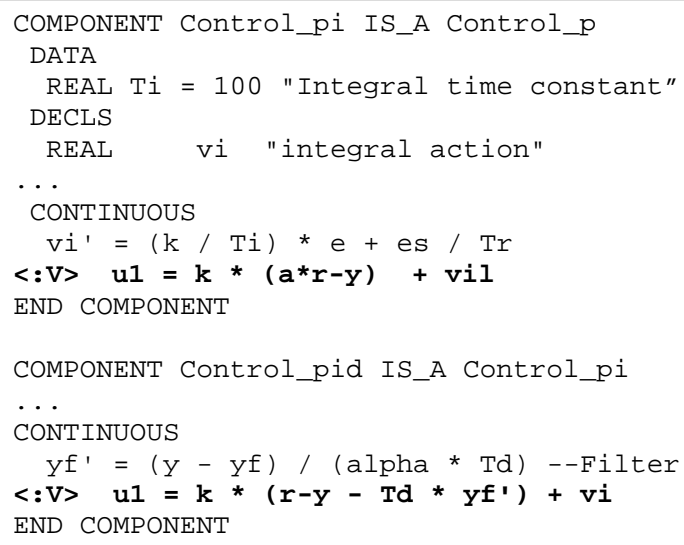

Figure 11: Use of virtual equations in the EL code of the PI and PID components

\subsection{Gate automation system}

This component is used to control the spillway gates of the plant. The automation system is implemented as a program in the DISCRETE section of the component and it is represented in Fig. 12. It is executed each sampled time if the automation system is operating in automatic mode. Otherwise, the opening, closing or stopping commands must be ordered by the user during simulation.

Although the component is able to control a maximum number of eight gates (a higher number is unusual), there is an input parameter "N" to specify a lower number. The component has an analog input port to share the water level of the dam, other analog input port for the opening of each gate and an output port to command them.

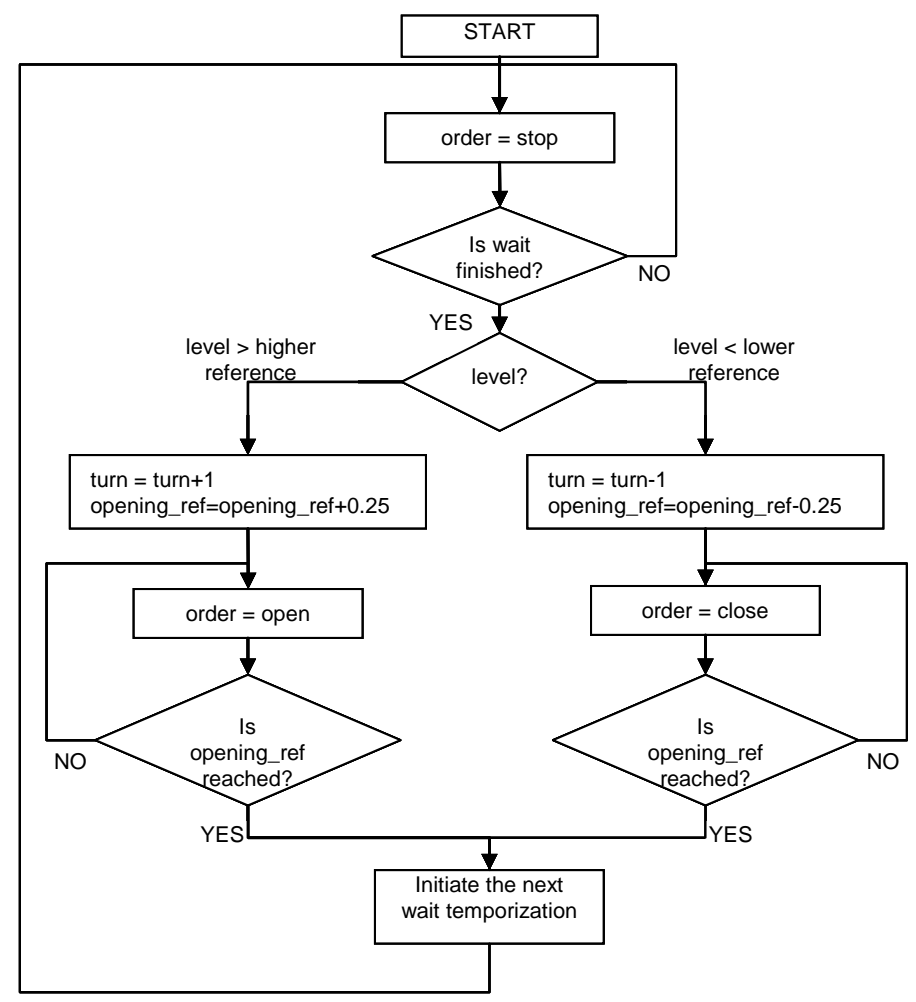

Figure 12: Block diagram of spillway gate automation system in automatic mode

\subsection{Automation system of a hydroelectric unit}

The automation program is implemented in the DISCRETE section of the component and it is executed each sample time. There are several parameters to be adjusted: sample time, reference level, stopping level, maximum and minimum loads, and son on. The component has several analog input ports to receive measurements of the 
unit: dam level, wicket gate position, turbine speed, power output, and so on. Also, it has output analog ports for sending the corresponding references to the controllers of the gate and runner blades.

\subsection{Hydroelectric unit}

Through aggregation of previous components, the hydroelectric unit component is modelled. It includes the control scheme of Fig. 5 in section 2. Figure 13 shows the component connections of the hydroelectric unit. Its components are the following:

- A Kaplan/Francis turbine.

- A generator.

- $\quad$ An automation system for the hydroelectric unit.

- $\quad$ A PID controller used as speed (or frequency) regulator and operating on the gate servomotor. It controls the turbine during the starting and stopping according to the automation system orders and the desired state of the unit.

- $\quad$ A PID controller for the runner blade positions. It receives the gate position in order to get the reference of the runner blade position according to the blade versus gate characteristic for optimal efficiency.

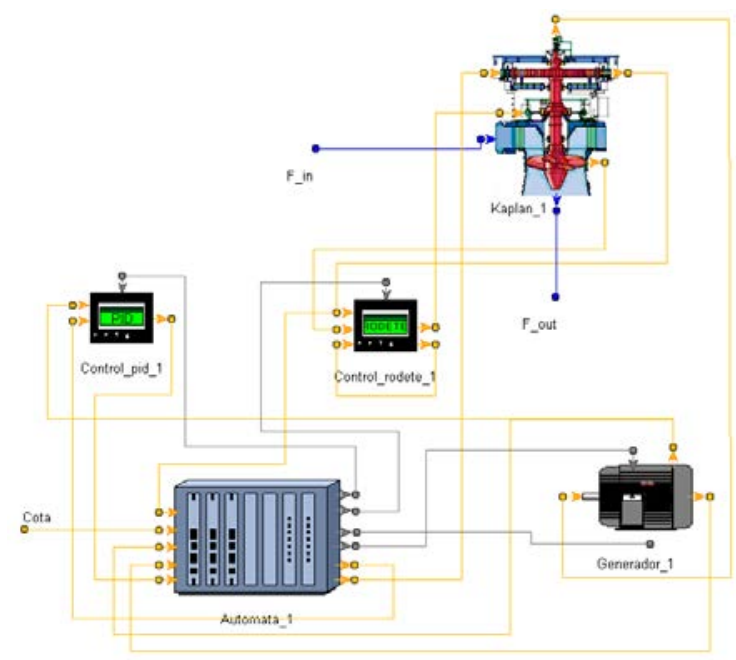

Figure 13: Connections of the hydroelectric unit

\subsection{Model of hydropower plant with run-of-river scheme}

So far the development of a library of hydropower plant components has been described. It can be used by undergraduate and graduate students in the teaching of hydropower system dynamics and for rapid testing of research ideas. The graphic symbols of these components are depicted in Fig. 18 in annexe I.

As first application of this library, a small hydropower plant model with low head run-of-river scheme is created. The connection scheme of this model is shown in annexe I in Fig. 19. The plant model consists of the following components:

- $\quad$ The dam

- $\quad$ The spillway

- $\quad$ Lower water reservoir

- $\quad$ Eight sliding gates

- $\quad$ The automation system of the gates

- $\quad$ Five hydroelectric unit that can be configured as Kaplan or Francis

- $\quad$ Fourteen dam intakes and outlets, one for each turbine and gate, and one for the spillway.

The plant utilizes the current river flow and head to generate as much power as possible while the upstream water level is controlled to maintain a minimum head. The sliding gates are used to control the reservoir level when the river flow exceeds the maximum turbine discharges and the dam level surpasses its highest reference.

Since it is desired to get a simulator for several hydropower plants, this model is able to be used to simulate 
plants with run-of-river scheme but with different configurations: different number of gates, number and type of turbines, and so on. In addition, each element has several parameters to be configured according to the specific plant. The model developed in this paper has a maximum number of eight gates and five hydroelectric units because most of hydropower plants do not exceed such numbers. However, the number of gates or hydroelectric units can be reduced cancelling their effects during simulation.

\section{Simulator}

After developing the general plant model, a simulation tool, a graphical user interface, for hydropower plants with run-of-river scheme has been designed. This tool is used to configure the model parameters, simulate this model and test its performance in different situations in order to optimize the plant operation and improve its productivity. In addition, it is intended as an educational tool, which can be used to experiment with and observe the effects of trying out new control configurations, and to understand and learn about hydropower plants. Moreover, in order to get a familiar application for the operator and to use it as a training tool, the graphical design is carried out according to the aspects of the SCADA of the plants of Endesa.

The main argument for the effectiveness of interactive and user-friendly graphical interfaces is the facility and speed of result interpretation. This characteristic is essential to improve the productivity of the relationship between user and computer. Other important fact is the time reduction for learning and training provided by graphical environments [16].

The simulator has been designed using Visual Basic 6.0 because experiments generated by EcosimPro can be easily integrated in Visual Basic applications. For this purpose there are an interface based on a small number of functions: to load the experiment, start its execution, pause it, read or modify variables values, and so on. It is not necessary to install EcosimPro to run the simulator; only a dynamic link library called EcoViewer is required. It is a DLL ActiveX that provides the programmer with a series of objects together with their associated methods. Also, it works as interface between the model experiment and the user application.

In Fig. 14 the development and structure of the simulator is summarized. In EcosimPro the general model of hydropower plant is developed. After compiling the experiment of the plant, a text file with the data of the generated partition and a dynamic link library file with the data of the compiled experiment are generated. That is only done in the development stage.

When the graphical user interface starts, EcoViewer dll is loaded. Next it loads the previous files generated by EcosimPro with the partition and experiment data, so EcoViewer interface lets the communication between the simulator and the model experiment. Afterwards, the main screen of the tool is shown and the user takes control of it in order to load, configure or save parameters of the plant, or start the model simulation.

During the simulation EcoViewer, the solver executes the experiment sending and receiving data from the simulator through the EcoViewer interface. The data that can be handled in the application are interactive data, that is, not simply a numerical table, but also calculated during the execution. So, users are able to stop the simulation at a certain point, modify one or more parameters, and then resume the experiment, either from the beginning or from any other point to analyze their influence on the final result.

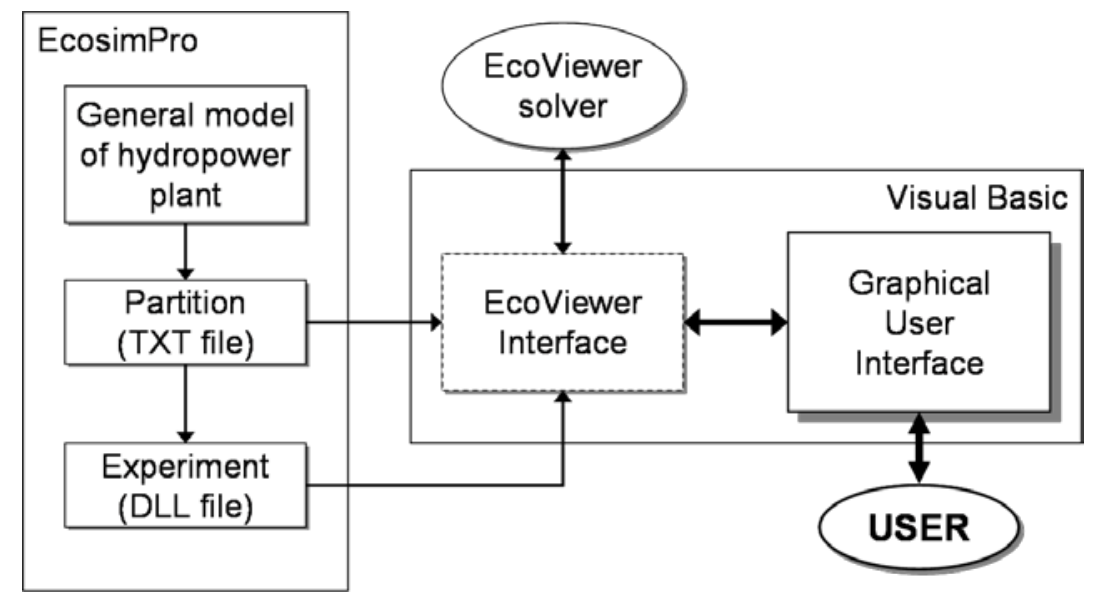


The main screen of the simulation tool can show information of the hydroelectric units, information of the gates or time responses of several variables of the units and gates. As example, Figure 15 shows the appearance of the simulator with data about the units: power output, discharge, efficiency, gate position, state and so on.

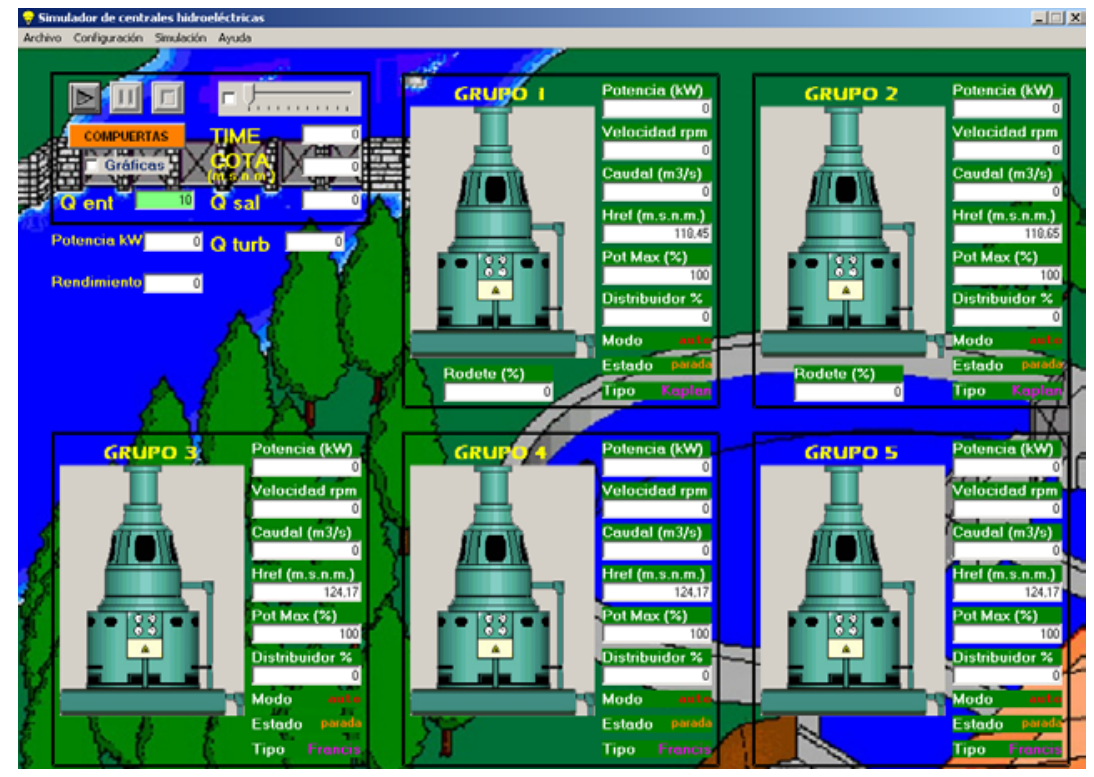

Figure 15: Simulator display (hydroelectric unit mode)

For training and educational use it is important that operators or students can quickly get started with their simulations. From the always visible main menu, drop-down menus facilitate easy access to windows where it is possible to configure the parameters of the different components, load the data of a specific plant, save these data into a file, start, pause or stop simulations, and so on. There is a set of reasonable default parameter values defined such that users can play around with a plant model even before they have full understanding of the meaning of all system parameters.

\section{Illustrative examples}

One of the main reasons that justify carrying out dynamic analysis of power plants is predicting its performance during different scenarios, including accidents, in order to improve and optimize this performance. After developing the tool, the simulator has been successfully verified through simulating three real hydropower plants with run-of-river scheme in Guadalquivir River: Villafranca, Marmolejo and El Carpio power plants. And it is currently being tested with other plants of the same river by Endesa operators. Next, the simulation results of these hydropower plants and the comparison with real data are shown. The validations are carried out with experimental results available to compare some of the variables of the plant: reservoir level, power, turbine gate position, and so on.

\section{1. "Villafranca” power station}

The main characteristics of "Villafranca" hydropower plant are the following [17]:

- Hydropower plant with run-of-river scheme built in 1948.

- Reservoir in Guadalquivir River $\left(0.63 \mathrm{Hm}^{3}\right)$.

- Dam with a maximum gross head of $8.5 \mathrm{~m}$.

- One spillway

- Four sliding gates to control the water level:

- $\quad$ Width: $13.5 \mathrm{~m}$

- $\quad$ Maximum opening: $5.5 \mathrm{~m}$

- Two hydroelectric units:

- Nominal capacity: 2.5 MW

- $\quad$ Specific speed: $187 \mathrm{rpm}$ 
- Kaplan turbines

- $\quad$ Nominal water flow: $36.5 \mathrm{~m}^{3} / \mathrm{s}$

Next, the input flow of the river to the reservoir is changed in three different simulations in order to study the plant performance. First, an input flow of $30 \mathrm{~m}^{3} / \mathrm{s}$ is used, then, a flow of $60 \mathrm{~m}^{3} / \mathrm{s}$, and finally, $100 \mathrm{~m}^{3} / \mathrm{s}$. In all cases, the units are initially stopped and the initial water level of the dam is $118.45 \mathrm{~m}$ above sea level.

For the first case, table 2 shows the stationary results of the main variables used for the validation after one hour. Only unit 1 is operating because it is enough to discharge the flow and control the water level. The reference level of this unit is $118.45 \mathrm{~m}$.

Table 2: Results for an input flow of $30 \mathrm{~m}^{3} / \mathrm{s}$ (Villafranca Station)

\begin{tabular}{|c|c|c|c|}
\hline \multicolumn{4}{|c|}{ UNIT 1 } \\
\hline & Power (kW) & Gate (\%) & Level (m) \\
\hline Simulation data & 2476 & 89 & 118.45 \\
\hline Real data & 2500 & 87 & 118.44 \\
\hline
\end{tabular}

In the same way, in table 3 stationary results after one hour for the second case are shown. Both units come into operation to control the water level according to the reference of the second unit, $118.65 \mathrm{~m}$.

Table 3: Results for an input flow of $60 \mathrm{~m}^{3} / \mathrm{s}$ (Villafranca Station)

\begin{tabular}{|c|c|c|c|c|c|}
\hline \multicolumn{2}{|c|}{} & \multicolumn{2}{c|}{ UNIT 1 } & \multicolumn{2}{c|}{ UNIT 2 } \\
\hline & Level (m) & Power (kW) & Gate (\%) & Power (kW) & Gate (\%) \\
\hline $\begin{array}{c}\text { Simulation } \\
\text { data }\end{array}$ & 118.65 & 2475 & 87 & 2475 & 87 \\
\hline Real data & 118.64 & 2500 & 88 & 2440 & 84 \\
\hline
\end{tabular}

The main differences between the model and the real plant are found in the transient responses. Although these simulation results are not exactly the same than the real data, the stationary results are very good.

In the third case, the two units are not able to control by themselves the water level of the reservoir, because the input flow of the river is greater than the maximum discharge of the turbines. Therefore, the automation system of the gates comes into operation to regulate the water level between the references 118.68 and $118.73 \mathrm{~m}$. After simulation, about 7200 seconds, the units discharge a total flow of $69.69 \mathrm{~m}^{3} / \mathrm{s}$, generating a total power of 5001 $\mathrm{kW}$ with efficiency about $91 \%$. These results are shown in Fig. 16, where the simulation time responses of the hydroelectric units are depicted. The gates 1, 2 and 3 open 0.25 m each one and discharge a total flow of 70.92 $\mathrm{m}^{3} / \mathrm{s}$. This simulation could not be validated due to the impossibility of testing the plant and the inexistency of experimental results in the same conditions, but it can give an idea of the plant response. 

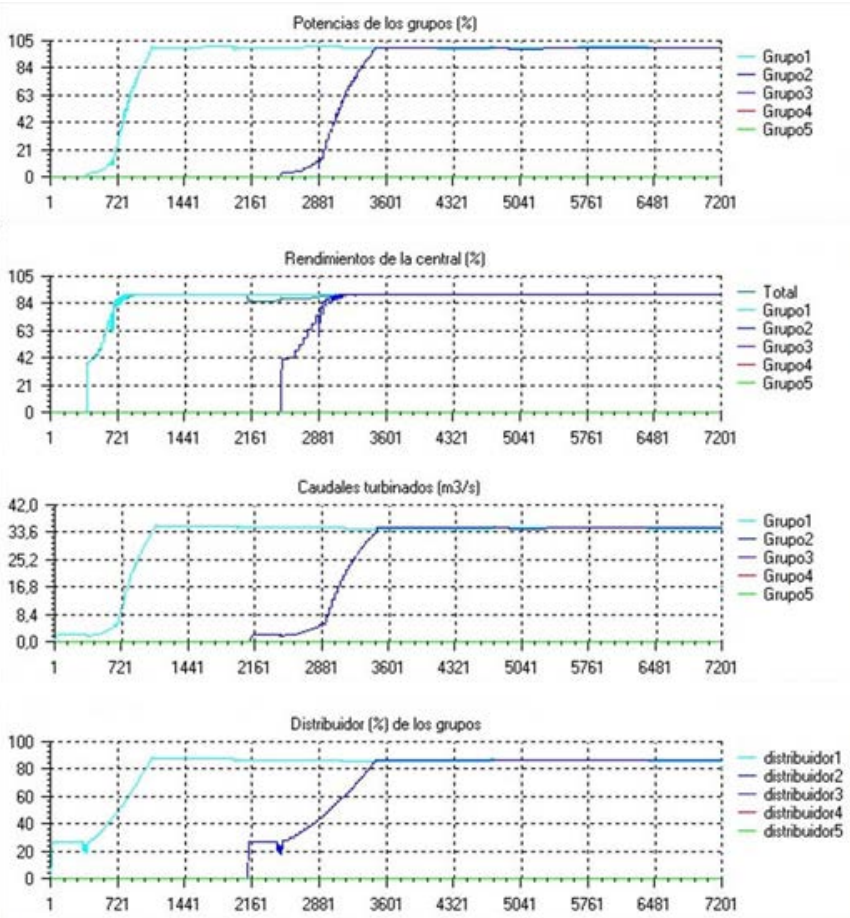

Figure 16: Time response of the units for an input flow of $100 \mathrm{~m}^{3} / \mathrm{s}$ : power (\%), efficiencies (\%), flows $\left(\mathrm{m}^{3} / \mathrm{s}\right.$ ) and gate positions (\%) (Sky blue: unit 1; navy blue: unit 2)

In Fig. 17 it is shown a zoom of the power time response of the first unit between the seconds 715 and 831 . The hydroelectric group is coupled to the grid and non-minimum phase behaviours can be observed each time that the governor control increases the load in order to control the reservoir level.

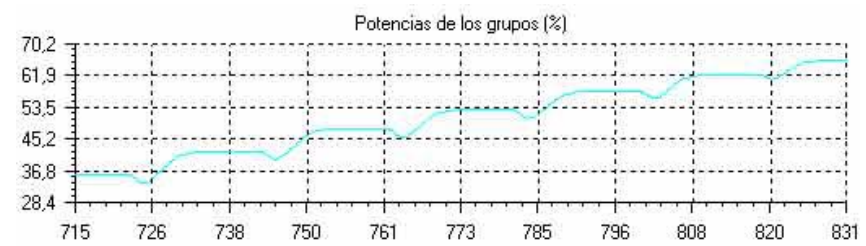

Figure 17: Zoom of power time response of unit 1

\section{2. "El Carpio" power station}

The main characteristics of "El Carpio" hydropower plant are the following [18]:

- Hydropower plant with run-of-river scheme built in 1922.

- Reservoir in Guadalquivir River $\left(2.54 \mathrm{Hm}^{3}\right)$.

- Dam with a maximum gross head of $20.4 \mathrm{~m}$.

- One spillway

- Six sliding gates to control the water level:

- Width: $18.5 \mathrm{~m}$

- Maximum opening: $8.5 \mathrm{~m}$

- Three hydroelectric units:

- Nominal capacity: 3 MW

- $\quad$ Specific speed: $214 \mathrm{rpm}$

- Francis turbines

- Nominal water flow: $19 \mathrm{~m}^{3} / \mathrm{s}$

As example, table 4 shows the stationary results in the same way as the previous case of Villafranca power station. An input flow of $50 \mathrm{~m}^{3} / \mathrm{s}$ is used, the units are initially stopped and the initial water level of the dam is $137.1 \mathrm{~m}$ above sea level. The three units come into operation to control the water level according to the reference of the third unit, $137.2 \mathrm{~m}$. 
Table 4: Results for an input flow of $50 \mathrm{~m}^{3} / \mathrm{s}$ (El Carpio Station)

\begin{tabular}{|c|c|c|c|c|c|c|c|}
\hline \multicolumn{2}{|c|}{} & \multicolumn{2}{c|}{ UNIT 1 } & \multicolumn{2}{c|}{ UNIT 2 } & \multicolumn{2}{c|}{ UNIT 3 } \\
\hline & Level (m) & $\begin{array}{c}\text { Power } \\
(\mathrm{kW})\end{array}$ & $\begin{array}{c}\text { Gate } \\
(\%)\end{array}$ & $\begin{array}{c}\text { Power } \\
(\mathrm{kW})\end{array}$ & $\begin{array}{c}\text { Gate } \\
(\%)\end{array}$ & $\begin{array}{c}\text { Power } \\
(\mathrm{kW})\end{array}$ & $\begin{array}{c}\text { Gate } \\
(\%)\end{array}$ \\
\hline $\begin{array}{c}\text { Simulation } \\
\text { data }\end{array}$ & 137.21 & 2640 & 98 & 2640 & 98 & 2230 & 83.5 \\
\hline Real data & 137.2 & 2520 & 96 & 2500 & 96 & 2090 & 81 \\
\hline
\end{tabular}

\section{3. "Marmolejo" power station}

The main characteristics of "Marmolejo" hydropower plant are the following [19]:

- Hydropower plant with run-of-river scheme built in 1962.

- Reservoir in Guadalquivir River $\left(12.8 \mathrm{Hm}^{3}\right)$.

- Dam with a maximum gross head of $16.6 \mathrm{~m}$.

- One spillway

- Seven sliding gates to control the water level:

- Width: $15 \mathrm{~m}$

- Maximum opening: $6 \mathrm{~m}$

- Two hydroelectric units:

- Nominal capacity: 10.6 MW

- Specific speed: $200 \mathrm{rpm}$

- Kaplan turbines

- Nominal water flow: $60 \mathrm{~m}^{3} / \mathrm{s}$

In this case, table 5 shows the stationary results with an input flow of $100 \mathrm{~m}^{3} / \mathrm{s}$. The units are initially stopped and the initial water level of the dam is $191.6 \mathrm{~m}$ above sea level. Firstly, only the unit 1 comes into operation but when the water level exceeds the level reference of the second unit $(191.65 \mathrm{~m})$, this one has to start its operation to control the water level.

Table 5: Results for an input flow of $100 \mathrm{~m}^{3} / \mathrm{s}$ (Marmolejo Station)

\begin{tabular}{|c|c|c|c|c|c|}
\hline \multicolumn{2}{|c|}{} & \multicolumn{2}{c|}{ UNIT 1 } & \multicolumn{2}{c|}{ UNIT 2 } \\
\hline & Level (m) & Power (kW) & Gate (\%) & Power (kW) & Gate (\%) \\
\hline $\begin{array}{c}\text { Simulation } \\
\text { data }\end{array}$ & 191.65 & 8064 & 90 & 7382 & 79 \\
\hline Real data & 191.64 & 8000 & 91 & 7200 & 76 \\
\hline
\end{tabular}

As in the case of Villafranca power plant, the main differences between simulations and the real plants are found in the transient responses. Simulation results for Villafranca power plant are better than for other stations because the simulator was initially developed for this plant, and then extended for other stations. However, the simulator gets good results in the other plants.

\section{CONCLUSIONS}

In this paper a flexible component library for hydropower plants has been designed using OOM methodology with EcosimPro software. As first application of this library a general model of small hydropower plant with run-of-river scheme is created. This model can be used to simulate different plants with run-of-river scheme changing its configuration parameters. On the other hand, a graphical user interfaced is developed in Visual Basic as environment for configuration and control the simulation of the model.

The simulator is validated using data from three real hydropower plants. The results exhibit good agreement between the developed tool and the real data. Therefore, the tool can be used to analyze the behaviour of other plants with run-of-river scheme and improve some aspects like system stability, installation performance or reduction of starting operations. Also, the simulator can be use to study in an approximated way the behaviour of the plant in unusual or unexpected conditions like a great flood of the river. 


\section{Acknowledgment}

This work has been partially supported by Endesa Generacion Company. This support is gratefully acknowledged. Moreover, J. Garrido thanks the FPU fellowship (Ref. AP2006-01049) of the Spanish Ministry of Science and Innovation.

\section{References}

[1] Penche, C. 1998. Layman's handbook on how to develop a small hydro site. Directorate- General for Energy of ESHA, DG XVII - 97/010.

[2] Mataix, C. 1986. Mecánica de fluidos y máquinas hidráulicas. Ediciones del Castillo S.A. $2^{\text {a }}$ Ed. ISBN 84-219-0175-3.

[3] Neujahr, M.; Cassana, I; Silveira, A.. 2007. A new approach for the design of electric power system software using object oriented modelling. Electrical Power and energy Systems, Vol. 29, pp. 505-513.

[4] Zhou, E. Z. 1996. Object-oriented programming, $C++$ and power system simulation. IEEE Transactions on Power Systems, Vol. 11, No. 1, pp. 206-215.

[5] Dillon, T. S.; Chang, E. 1994. Solution of power system problems through the use of the object-oriented paradigm. International Journal of Electrical Power and Energy Systems, Vol. 16, No 3, pp. 157-165.

[6] Lu, S.; Hogg, B. W. 1995. An Object-Oriented Power Plant Adaptive Control System Design Tool. IEEE Transactions on Energy Conversion, Vol. 10, No. 3, pp. 600-605.

[7] Manzoni, A.; e Silva, A. S.; Decker, I. C. 1999. Power System Dynamics Simulation Using ObjectOriented Programming. IEEE Transactions on Power Systems, Vol. 14, No. 1, pp. 249-255.

[8] Tomschi, U.; Jäckisch, H.; Newald, R.2006. Operator guidance simulator: A new power plant training tool concept. 5th Symposium on Power Plants and Power Systems Control, pp. 327-332.

[9] Garrido, J.; Zafra, A.; Vázquez, F. 2007. Modelado y Simulación de Centrales Hidráulicas. XXVIII Jornadas de Automática. Huelva (Spain).

[10] Working Group on Prime Mover and Energy Supply. 1992. Hydraulic turbines and turbine control models for system dynamic studies. IEEE Transactions on Power Systems Vol. 7, No. 1, pp. 167-179.

[11] Kosterev, D. 2004. Hydro Turbine-Governor Model Validation in Pacific Northwest. IEEE Transactions on Power Systems Vol. 19, No. 2, pp. 1144-1149.

[12] Pandit, S.; Soman, S. A.; Khaparde, S. A. 2000. Object-oriented design for power system applications. IEEE Computer Applications in Power, Vol. 13, Issue 4, pp. 43-47.

[13] E. A. International. 2005. EcosimPro User Manual. EcosimPro V.3.4.

[14] Cho, Y. S.; Park, J.; Jang, G. 2007. A novel tool for transient stability analysis of large-scale power systems: Its application to the KEPCO system. Simulation Modelling Practice and Theory, Vol. 15, pp. 786-800.

[15] Agüera, J. 1996. Mecánica de fluidos incompresibles. Editorial Ciencia. 4ª Ed. ISBN 84-86204-73-9.

[16] Kober, F.; Manzoni, A.; Lemos, F. A. B. 2003. An object-oriented approach to development and integration of graphical user interface and power system framework. Proceedings of the IEEE power tech conference, Vol 3. pp. 23-26.

[17] Endesa Generación. 2002. Plan de operación normal de la central hidráulica de Villafranca. Unidad de Producción Hidráulica Sur.

[18] Endesa Generación. 2004. Plan de operación normal de la central hidráulica de El Carpio. Unidad de Producción Hidráulica Sur.

[19] Endesa Generación. 2002. Plan de operación normal de la central hidráulica de Marmolejo. Unidad de Producción Hidráulica Sur.

\section{ANNEXE I: COMPONENT LIBRARY SYMBOLS AND MODEL OF THE HYDROPOWER PLANT WITH RUN-OF-RIVER SCHEME}




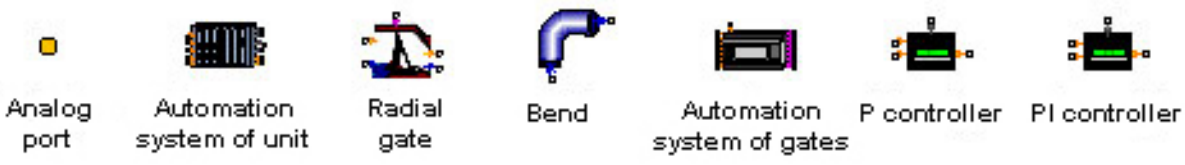

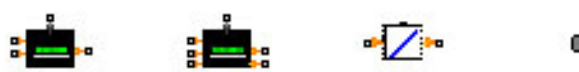

PID controller Runner blade Converter Digital Dam Lower water Expansion
controller

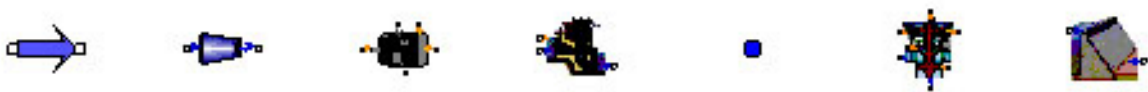

Damoutlet Constraction Generator Hydroelectric Hydraulic Kaplan/Francis Spillway unit port turbine

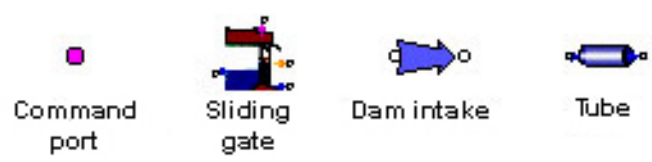

Figure 18: Component symbols of the library

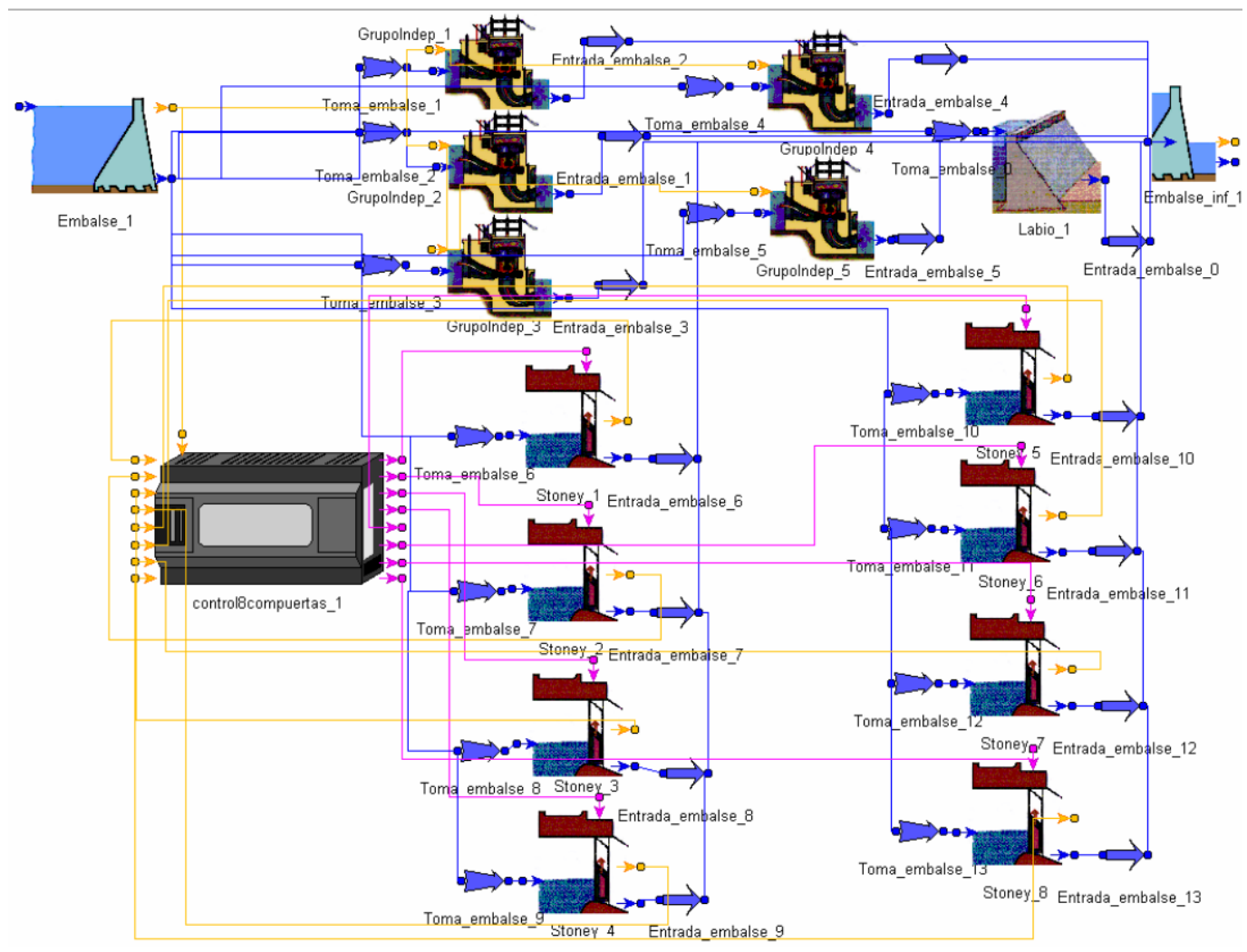

Figure 19: Model of hydropower plant with run-of-river scheme 